\title{
Evaluation of a Safe Motherhood project in Ntcheu district, Malawi
}

This article was published in the following Dove Press journal:

International Journal of Women's Health

12 December 2014

Number of times this article has been viewed

\author{
Dennis Mseu' \\ Betty Mkwinda Nyasulu ${ }^{2}$ \\ Sadandaula Rose Muheriwa ${ }^{3}$ \\ 'Nurses and Midwives Council \\ of Malawi, Lilongwe, Malawi; ${ }^{2}$ Basic \\ Studies Department, Kamuzu College \\ of Nursing, University of Malawi, \\ Lilongwe, Malawi; ${ }^{3}$ Department \\ of Maternal and Child Health, \\ Kamuzu College of Nursing, \\ University of Malawi, Lilongwe, \\ Malawi
}

Purpose: This study evaluated knowledge and practices of childbearing women on key childcare practices within the Safe Motherhood project, administered by the Ntcheu District Health Office in the Republic of Malawi. The study excluded men and elderly women.

Methods: The design was cross-sectional, and utilized quantitative and qualitative data collection and analysis procedures. Data were also collected through review of participant health records. Results: Although the findings showed that all participants $(100 \%, \mathrm{n}=400)$ had general knowledge on maternal and child health care, they did not have comprehensive information, and few mothers were practicing the recommended key child health care practices. Only $42.4 \%(n=170)$ knew the appropriate number of visits a woman should make to the antenatal clinic, and very few knew the appropriate time at which to access antenatal care. Only $55 \%(n=220)$ of participants breastfed their babies exclusively. Some participants introduced supplementary feeds as early as a month after birth, and not all women delivered at the health facility. Failure to actively involve men and elderly women in maternal and child health issues had a negative impact on women's ability to fully implement key maternal and childcare practices.

Conclusion and recommendations: There is a need to actively involve men and elderly women in maternal and child health issues since, in the ideal Malawian context, a child is raised not just by the mother, but also by all who live in the village. Additionally, elderly women are the guardians of members of the childbearing group, and are a traditional reservoir of experience into which young women can tap. There is also a need to engage Community Nurse-Midwives in facilitating women's groups that provide comprehensive antenatal information to mothers, who may then put knowledge into practice.

Keywords: health-seeking behavior, key childcare practices, exclusive breastfeeding, men's participation

\section{Introduction}

The Republic of Malawi has one of the highest maternal and child mortality rates in the world. Statistics indicate that, of 100,000 births, 675 women die while giving birth each year. Child mortality in Malawi is currently estimated at 50/1000 live births. ${ }^{1}$

\section{Background}

In 2005 the Malawi Ministry of Health, through the Ntcheu District Health Office, initiated a community-based Safe Motherhood project using a women's group model. The first phase of this project was implemented from 2005 to 2008 . The second phase started in 2010 and was expected to phase out in 2013. The project aims to improve women's access to maternal health care; empower women to implement strategies to improve maternal, neonatal and under-fives' health, and implement key childcare practices.
Correspondence: Dennis Mseu Nurses and Midwives Council of Malawi, PO Box 3036I,

Lilongwe 3, Malawi

Tel +2659994728 10

Fax +265 | 773932

Email dennismseu@yahoo.co.uk
International Journal of Women's Health 2014:6 I045-1055

Dovepress

http://dx.doi.org/10.2147/IJWH.S40109 (c) (1) (5) 2014 Mseu et al. This work is published by Dove Medical Press Limited, and licensed under Creative Commons Attribution - Non Commercial (unported, v3.0) License. The full terms of the License are available at http://creativecommons.org/licenses/lby-nc/3.0/. Non-commercial uses of the work are permitted without any further permission from Dove Medical Press Limited, provided the work is properly attributed. Permissions beyond the scope of the License are administered by Dove Medical Press Limited. Information on how to request permission may be found at: http://www.dovepress.com/permissions.php 
The project established 134 women's groups in the areas of Mpando, Kwataine, Makwangwala, Champiti, Phambala, and Tsikulamowa. It disseminates messages on safe motherhood using a participatory learning action (PLA) cycle. In this cycle women, guided by a female Health Surveillance Assistant (HSA), meet monthly to work through the action cycle to identify and prioritize key Maternal and Neonatal Health (MNH) problems; design and implement strategies to address their MNH problems; and evaluate progress. The model is based on trials regarding the positive contribution of a community action cycle focused on women's groups. ${ }^{2-8}$

The purpose of this research was to determine the extent to which the Safe Motherhood project, using the women's group model, influenced women's ability to implement key maternal and child health care practices. This paper assesses women's knowledge of maternal and newborn health care services and women's ability to implement them, as presented in subthemes in the results section.

\section{Methods}

\section{Research design}

This was a cross-sectional descriptive study that used quantitative and qualitative approaches. For the quantitative part, data were collected using a structured questionnaire developed following Community Safe Motherhood project guidelines. The tool solicited demographic and socioeconomic characteristics of respondents, and their relevant knowledge and practices.

For the qualitative part, data were collected through focus group discussions (FGDs). Ten FGDs were conducted with community women in the randomly-sampled villages. Data were collected using a semi-structured interview guide. The tool solicited information on women's experiences with maternal and child health services. The interviews were audio-recorded, and a research assistant took notes during each interview to supplement the transcripts. The purpose of the study was explained before the beginning of each interview, and respondents were given the opportunity to refuse or accept participation, and to provide their informed consent. At the end of each discussion, the assistant read out a summary of the notes to validate the information. Health records of participants were also reviewed to collect data.

\section{Sample and setting}

The sample size was calculated on the proportion of women with children aged under 5 years in Ntcheu district, a 95\% confidence interval, and an allowable precision error of $5 \% .{ }^{9}$
A sample that gave a $95 \%$ power to detect significance differences at a 5\% level of significance was 400 .

Random sampling was used to select villages from where ten respondents were chosen, totaling 400, using convenience sampling. This method was used because the study aimed to seek individuals with the specific trait of having obtained firsthand information on utilization of the maternal and child health services with the Community Safe Motherhood project. For the qualitative part, purposive sampling was used to recruit the participants.

The study was conducted in Ntcheu district, located in the southern end of the central region of Malawi. It borders with Balaka district to the southeast, Mangochi district to the northeast, Neno district to the south, Dedza district to the north, and the Republic of Mozambique to the west (Figure 1 and 2). The district has a total population of $370,988 .{ }^{10}$ The literacy rates for males and females are $76 \%$ and $52 \%$ respectively. ${ }^{11}$

\section{Ethical considerations}

Permission to conduct the survey in the project area was granted by the Safe Motherhood project manager, the district health officer, and the officers in charge of the health centers. The researcher and 15 research assistants who were trained in consenting process and interviewing skills, selected the clients, and collected the data. Eligible clients were informed

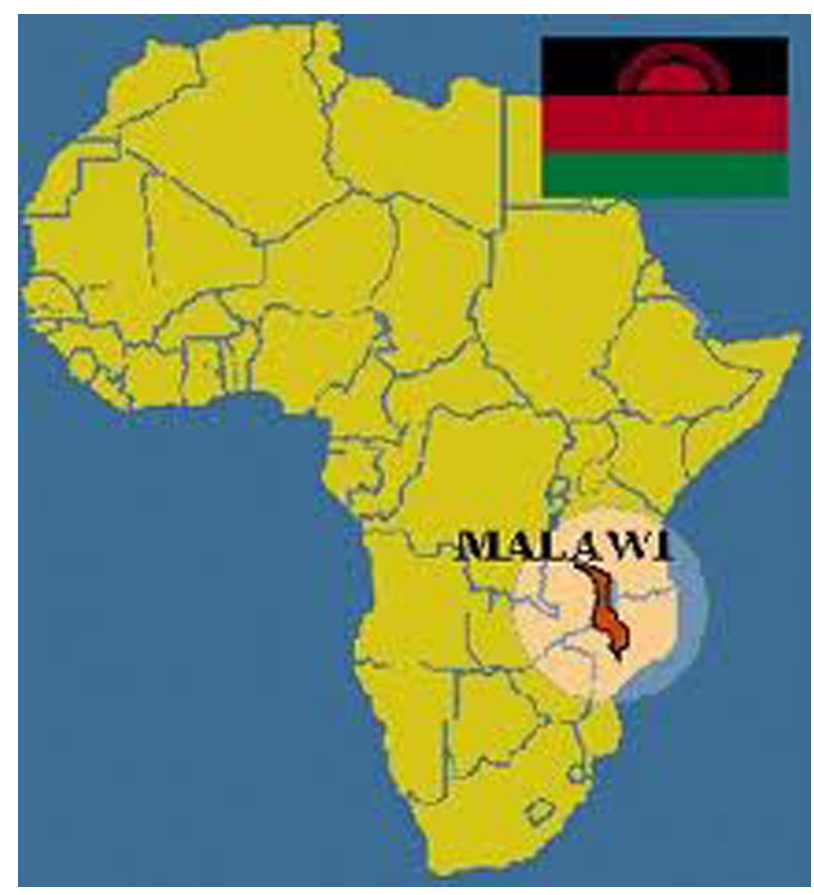

Figure I Map of Africa showing Malawi. 


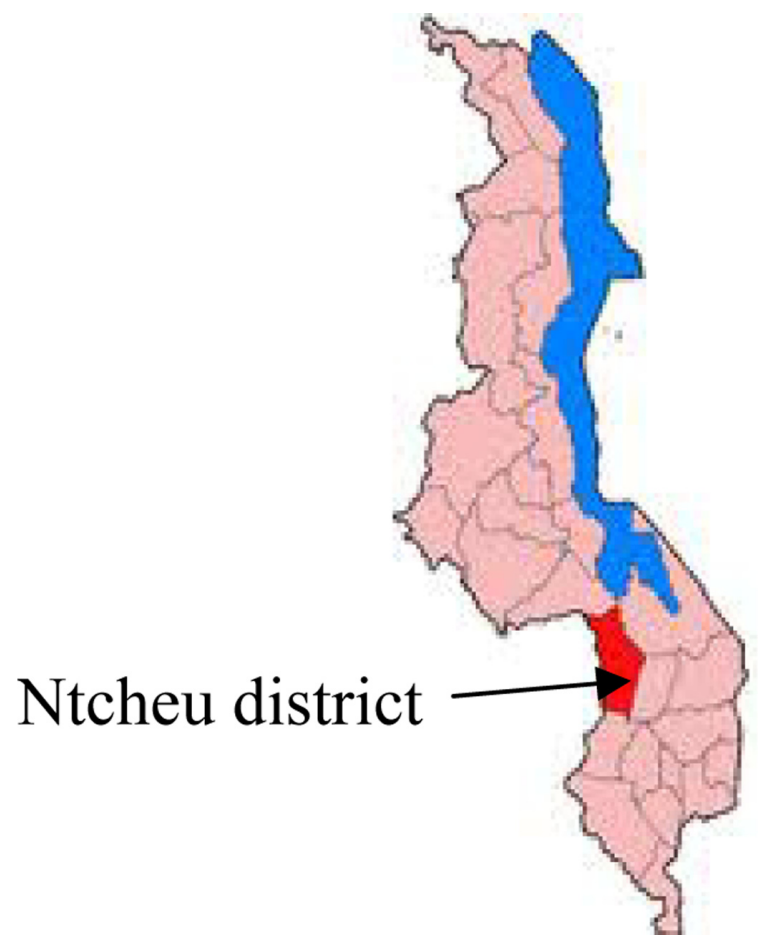

Figure 2 Map of Malawi showing Ntcheu district.

about the study and indicated their consent by signing a form, or providing a thumbprint if they were illiterate. The questionnaire was orally administered to the respondents, and the researcher manually annotated their responses on the questionnaire form. Interviews were conducted in Chichewa (the national language of Malawi) and lasted about 30 minutes. In-depth interviews lasted 30-45 minutes. Anonymity and confidentiality of the respondents and their responses was maintained throughout the study. All research activities were performed in accordance with guidelines established by the Research Department at Leeds Metropolitan University (Leeds, West Yorkshire, UK).

\section{Data management and analysis}

Descriptive statistics were computed using public domain Epi Info software (Centers for Disease Control and Prevention, Atlanta, GA, USA). Demographic variables were cross-tabulated with outcome variables that measured practice. Test of significance difference between categorical variables was done using chi-square test at a $5 \%$ level of significance.

Qualitative data were audio recorded, transcribed verbatim, and translated into English. Field notes were taken to capture elements of the setting and of participants' demeanor, emotional responses, and other contextual factors that could not have been captured on an audio recording.
An independent person listened to the recorded interviews and verified the translation to ensure semantic correctness. Data were analyzed using a thematic analysis approach. ${ }^{12}$ Categories, themes, and subthemes on knowledge and practices emerged.

\section{Results \\ Demographic and socioeconomic characteristics of the participants}

Four hundred women participated in the study (Table 1). Their ages ranged from 15 to 49 years. The ages of the majority $(28 \%, \mathrm{n}=113)$ of respondents ranged from 20 to 24 years. Sixty percent of respondents $(n=240)$ were married. A large proportion $(41 \%, \mathrm{n}=164)$ of respondents were not educated, and the same proportion earned between US $\$ 1$ and US $\$ 13$ per month. A majority $(50 \%, n=200)$ of respondents lived at a distance of more than $5 \mathrm{~km}$ from their nearest health facility (Table 1).

Table I Demographic and socioeconomic characteristics of the respondents $(\mathrm{N}=400)$

\begin{tabular}{lll}
\hline Variable & $\begin{array}{l}\text { Number of } \\
\text { subjects }\end{array}$ & Percentage (\%) \\
\hline Age of respondents (years) & & \\
I5-19 & 30 & 7.5 \\
$20-24$ & 113 & 28.25 \\
$25-29$ & 96 & 24 \\
$30-34$ & 87 & 21.75 \\
$35-39$ & 47 & 11.75 \\
$40-44$ & 20 & 5 \\
$45-49$ & 7 & 1.75 \\
Marital status & & \\
Married & 240 & 60 \\
Divorced & 56 & 14 \\
Separated & 24 & 6 \\
Single & 40 & 10 \\
Widowed & 40 & 10 \\
Level of education & & \\
No education & 164 & 41 \\
Lower primary (standard I-5) & 98 & 24.5 \\
Upper primary (standard 6-8) & 58 & 14.5 \\
Lower secondary (form I-2) & 40 & 10 \\
Upper secondary (form 3-4) & 40 & 10 \\
Income per month (USD) & & \\
2.6-I3 & 164 & 41 \\
I3.I-26 & 100 & 25 \\
26.3-39 & 80 & 20 \\
39.5-52 & 36 & 50 \\
Above 52.6 & 20 & \\
Distance to the health facility & & \\
Less than I km & 40 & 10 \\
2 km-4 km & 160 & \\
Greater than 5 km & 200 & \\
\hline
\end{tabular}

Abbreviations: km, kilometer; USD, US dollars. 


\section{Knowledge of antenatal care}

All respondents knew that a pregnant woman was supposed to attend antenatal clinic. However, results revealed that only $42.4 \%(n=170)$ of respondents knew that a pregnant woman was supposed to make four visits to the antenatal clinic during the entire period of pregnancy. The majority of respondents $(59.1 \%, \mathrm{n}=236)$ mentioned third month as the most appropriate time to make their first visit to the antenatal clinic. When asked what services were provided at the antenatal clinic, respondents gave multiple responses as summarized in Table 2.

\section{Knowledge of place of delivery}

All respondents identified the health facility as an appropriate place where a pregnant woman should go for delivery of the baby.

\section{Knowledge of women on newborn care}

Care of the newborn was assessed on the measures of knowledge of breastfeeding, immunizations, postnatal check, and malaria prevention. Eighty-three percent $(n=332)$ of respondents indicated breastfeeding was best initiated within 30 minutes of delivery; $5 \%(n=20)$ after 1 hour, and 3\% $(n=12)$ after 2 hours (Figure 3 ). Nine per cent of respondents did not know the exact time to initiate breastfeeding.

Regarding respondents' knowledge of the right time to introduce other foods to the baby, $85.8 \%$ ( $n=343$ ) of respondents indicated 6 months. Three per cent of women $(n=12)$ indicated 1 month, $3 \%(\mathrm{n}=12)$ indicated 2 months, and $9.8 \%$ of respondents $(\mathrm{n}=39)$ indicated 5 months.

When asked about types of immunizations, the majority of women knew about available types of vaccines. Seventynine percent $(\mathrm{n}=316)$ were aware of measles immunizations, 77\% ( $\mathrm{n}=308)$ polio, 75\% ( $\mathrm{n}=300)$ Bacillus Calmette-Guérin

Table 2 Participants' knowledge of different services provided at the antenatal clinic $(\mathrm{N}=400)$

\begin{tabular}{lll}
\hline Antenatal care services & $\begin{array}{l}\text { Number of } \\
\text { subjects }\end{array}$ & Percentage (\%) \\
\hline Checking weight & $30 \mathrm{I}$ & 75.3 \\
Provision of anti-malarial drugs & 227 & 56.8 \\
Checking blood pressure & 237 & 59.3 \\
Checking level of blood Hb & 231 & 57.8 \\
HIV test & 242 & 60.5 \\
Provision of iron tablets & 222 & 55.5 \\
Abdominal palpation & 224 & 56.0 \\
Giving health information & 131 & 32.8 \\
\hline
\end{tabular}

Abbreviations: $\mathrm{Hb}$, hemoglobin; HIV, human immunodeficiency virus.

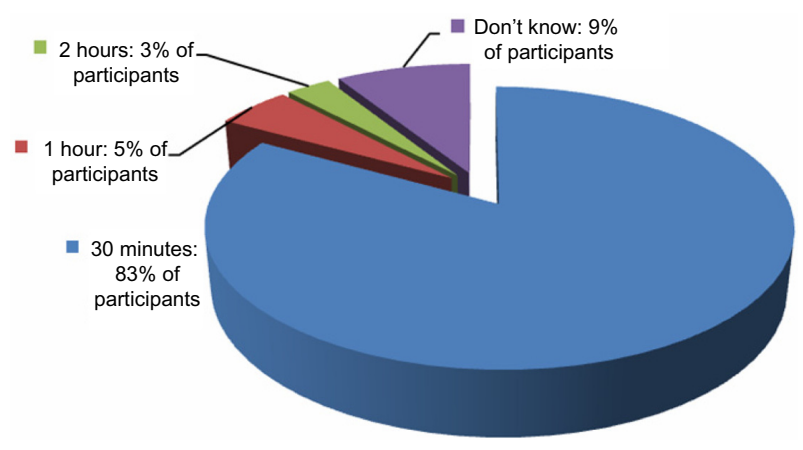

Figure 3 Knowledge of recommended time to start breastfeeding after delivery. Note: The recommended time to start breastfeeding is 30 minutes after delivery.

(BCG) tuberculosis vaccine, and 68\% $(\mathrm{n}=272)$ Pentavalent vaccine. Eight per cent $(\mathrm{n}=32)$ did not indicate knowledge of any type of vaccine. Many women, $85 \%(n=342)$ knew the right time to take their newly born babies back to health facility for postnatal check (Figure 4).

With regard to malaria prevention, women were assessed on knowledge of prevention of mosquito bites. All women mentioned use of insecticide-treated bed nets (ITNs) as the most effective method of preventing malaria infection.

\section{Actual practice: antenatal care}

Figure 5 shows the actual visits the respondents made to the antenatal clinic (ANC). The study compared the number of visits women made prior to the project (baseline data) and after the project (evaluation data). Forty-two percent of respondents $(\mathrm{n}=171)$ made the recommended four visits after the project as compared to $31.4 \%(n=126)$ of participants before the project. Chi-square test showed that there were statistically significant differences between levels of education and total number of visits women made to the antenatal clinic $(P=<0.5)$.

The FGD also revealed that women avoided attending antenatal clinic because they were afraid of an HIV test (Figure 6). Participant 7 reported: "Nowadays many women do not go to the antenatal clinic because they are afraid of having an HIV test." Laziness was also reported as one of the reasons for not attending antenatal clinic. "Some women are just lazy," reported Participant 10. When asked the exact gestation month in which respondents made their first visit to the ANC, the majority of respondents $(42.8 \%, \mathrm{n}=171)$ indicated the third month (Figure 7).

\section{Place of delivery}

Results revealed that $93.8 \%(\mathrm{n}=375)$ of respondents delivered at the health facility, $3 \%(\mathrm{n}=12)$ at the traditional birth attendant (TBA), and the remaining 3\% $(\mathrm{n}=12)$ delivered at home. Findings revealed a $16.1 \%$ increase in number of 


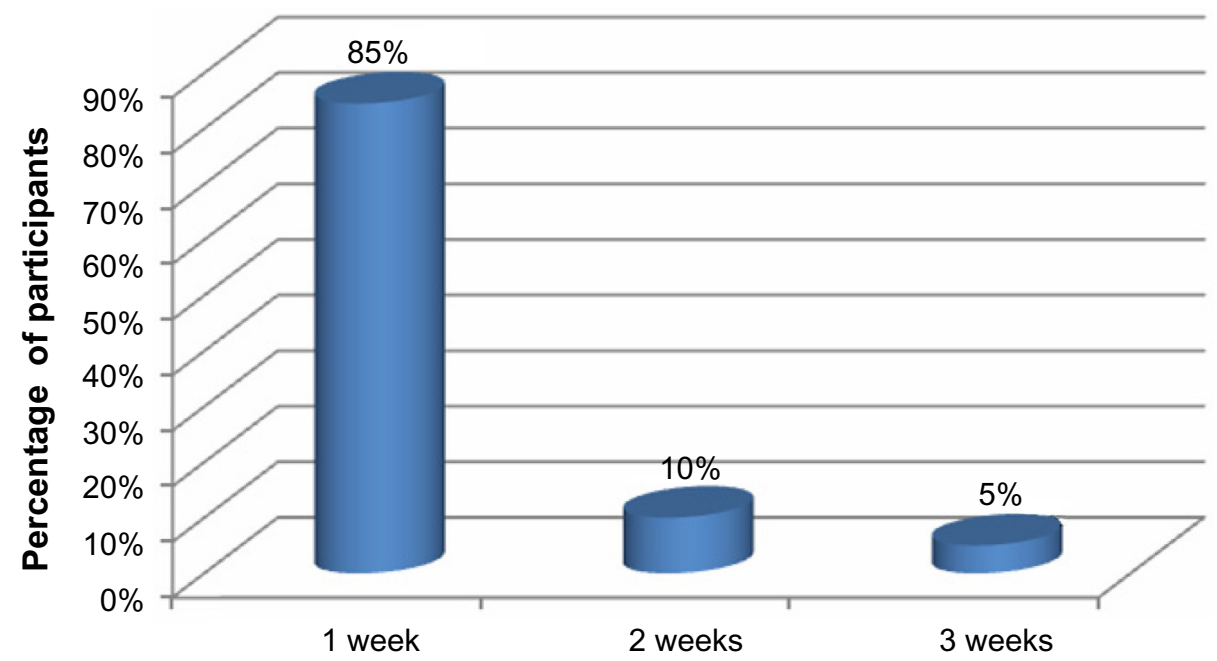

Figure 4 Participants' knowledge of the best time to return to the health facility for postnatal checkup.

hospital deliveries, as the baseline data indicated $77.7 \%$. Findings also showed that, of those who delivered at the health facility, only $87.1 \%(n=348)$ were assisted by a skilled birth attendant.

Respondent reasons given for not delivering at the health facility included long walking distance, religious beliefs (particularly for a participant identifying herself as of the Zionist faith) $(20 \%, n=1)$, and lack of money for transportation. Fear of facility midwives' abusive treatment was reported by all respondents who delivered at home. Participant 2 shared her experience: "We are always shouted at and at times we are beaten up by facility nurses." Participant 9 also shared her experience: "I have a colleague who had a bad experience of these nurses [midwives]. When she had gone to deliver her baby at the district hospital, nurses shouted at her before a large group of women and told her that she could not assist her as she feared contracting HIV [...] my friend is HIV positive".

\section{Actual practices regarding postnatal checkup}

When asked whether they had gone to the health facility for postnatal checkup, $84 \%(n=336)$ of participants reported that they had. Eighty-five percent of these $(n=286)$ reported to have gone after one week, $10 \%(\mathrm{n}=34)$ after 2 weeks, and 5\% $(n=17)$ after 3 weeks. For those who did not go for postnatal checkup, the reasons given included: long geographic distance $(33.3 \%, \mathrm{n}=5)$, lack of money for transportation $(20 \%$, $\mathrm{n}=3)$, and laziness and ignorance $(53.3 \% \mathrm{n}=8)$.

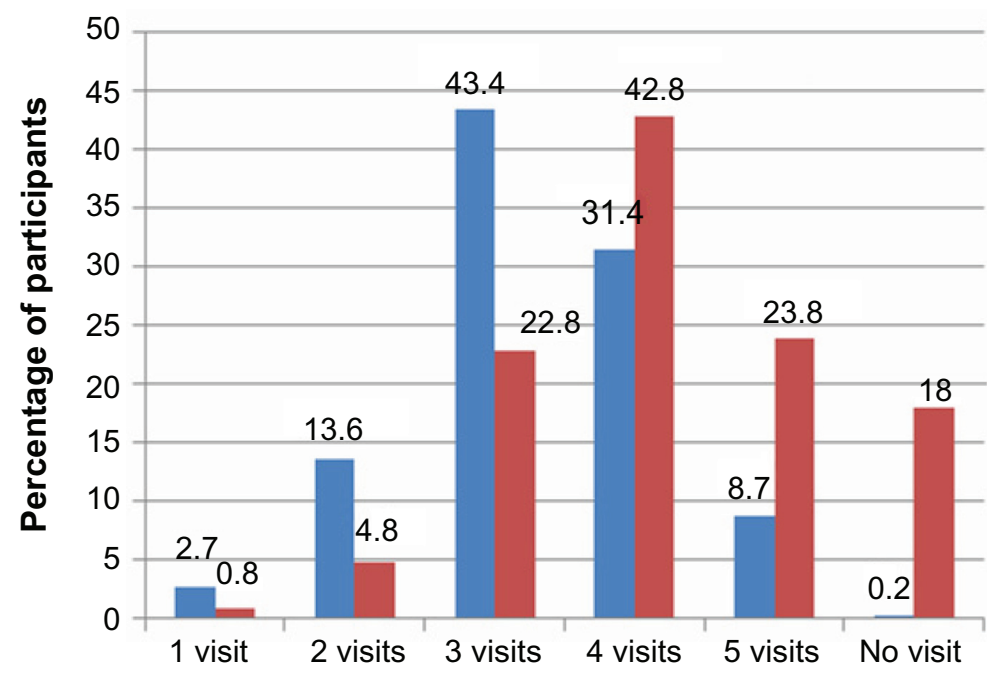

$\%$ Baseline

\% Evaluation

Figure 5 Comparison of number of visits to the antenatal clinic before and after initiation of the project.

Note: Baseline data reflect visits before initiation of the Safe Motherhood project; evaluation data reflect visits after initiation of the project. 


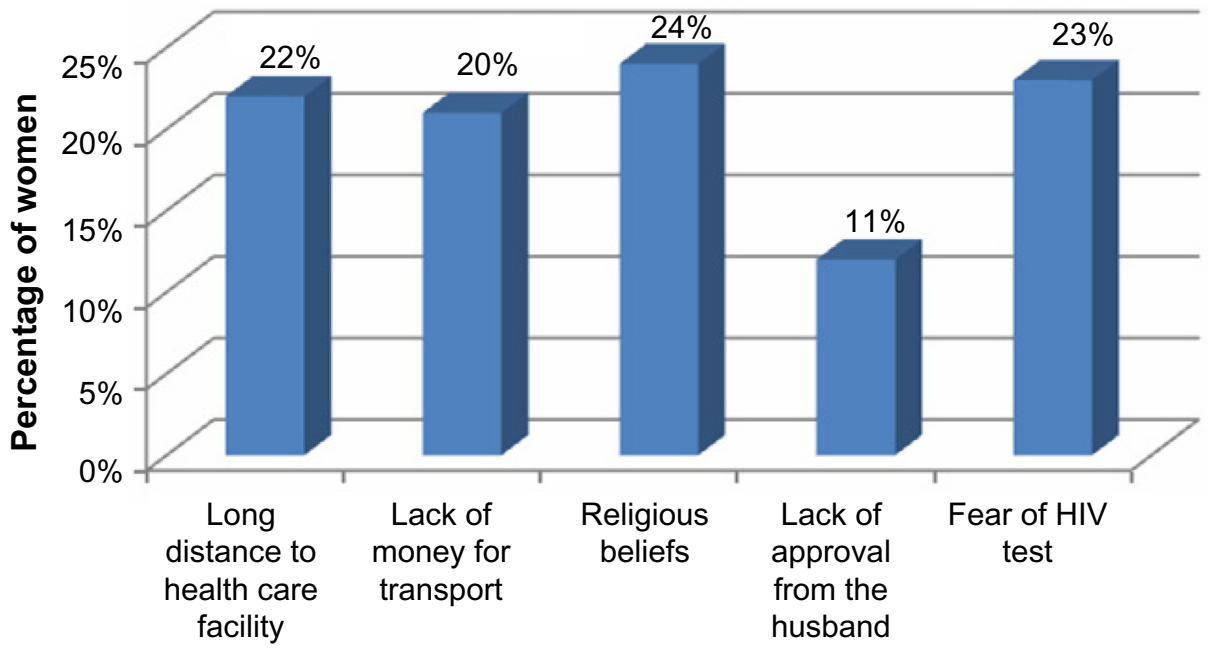

Figure 6 Reasons given by participants for not attending antenatal clinic. Abbreviation: HIV, human immunodeficiency virus.

\section{Actual practices on newborn care Infant feeding practices}

Eighty three percent $(n=332)$ of the respondents demonstrated adequate knowledge of recommended time to initiate breastfeeding, and $76 \%(n=304)$ started breastfeeding their babies within the recommended 30 minutes of delivery. Others initiated breastfeeding after an hour $(14 \%, \mathrm{n}=56)$ and $10 \%$ $(\mathrm{n}=40)$ after 2 hours.

As regards the introduction of supplementary feeds, $55 \%$ $(n=220)$ of respondents breastfed their babies exclusively and introduced supplementary feeds at 6 months. The remainder introduced supplementary feeds at 2 months $(10 \%, \mathrm{n}=18)$, 3 months ( $60 \%, \mathrm{n}=108), 4$ months ( $20 \%, \mathrm{n}=36)$, and 5 months $(10 \%, \mathrm{n}=18)$. The FGDs revealed that feeds were usually introduced to infants between 1 month and 3 months after birth because babies cried due to hunger. One participant shared her experience: "In our community women introduce feeds as early as 1 month because babies cry a lot and it's usually because they are hungry. Mostly it's the grandparents who facilitate this."

A review of records in November, 2011, revealed that 6\% $(n=24)$ of participants' children under the age of 5 years suffered from malnutrition and were referred to the nutritional rehabilitation unit.

\section{Actual practice regarding immunizations}

Seventy-four percent $(n=296)$ of all children under age five in the sampled households had received all available

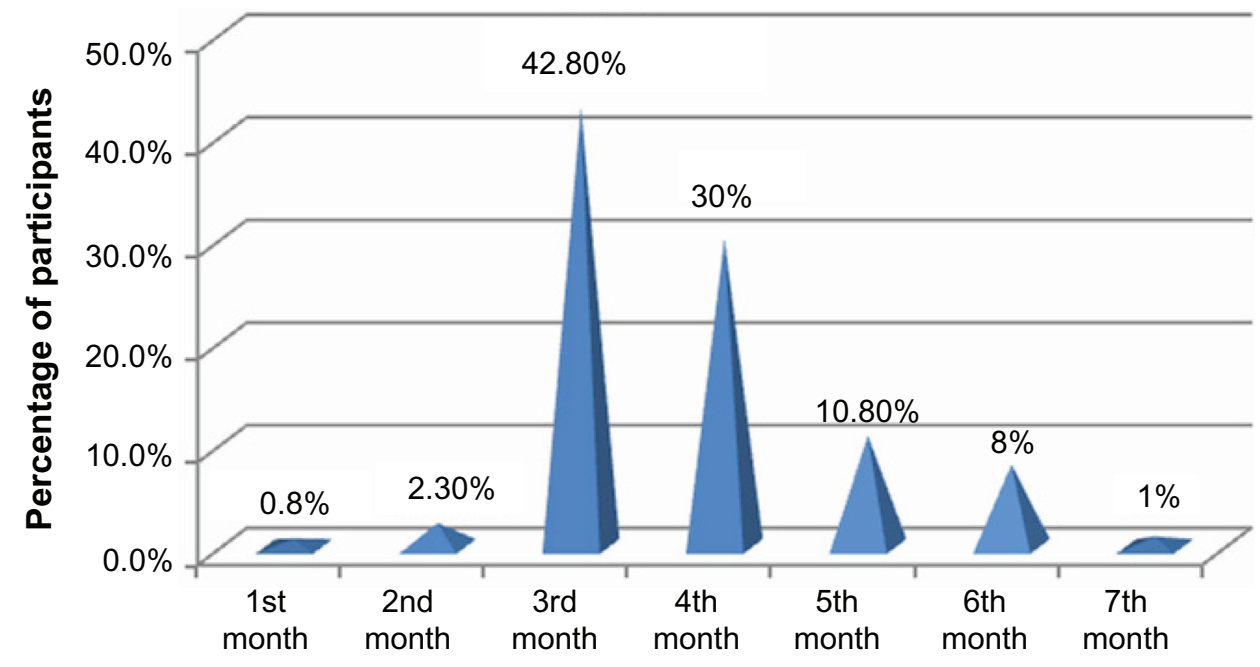

Figure 7 Gestation month at which respondents made first visit to the antenatal clinic. 


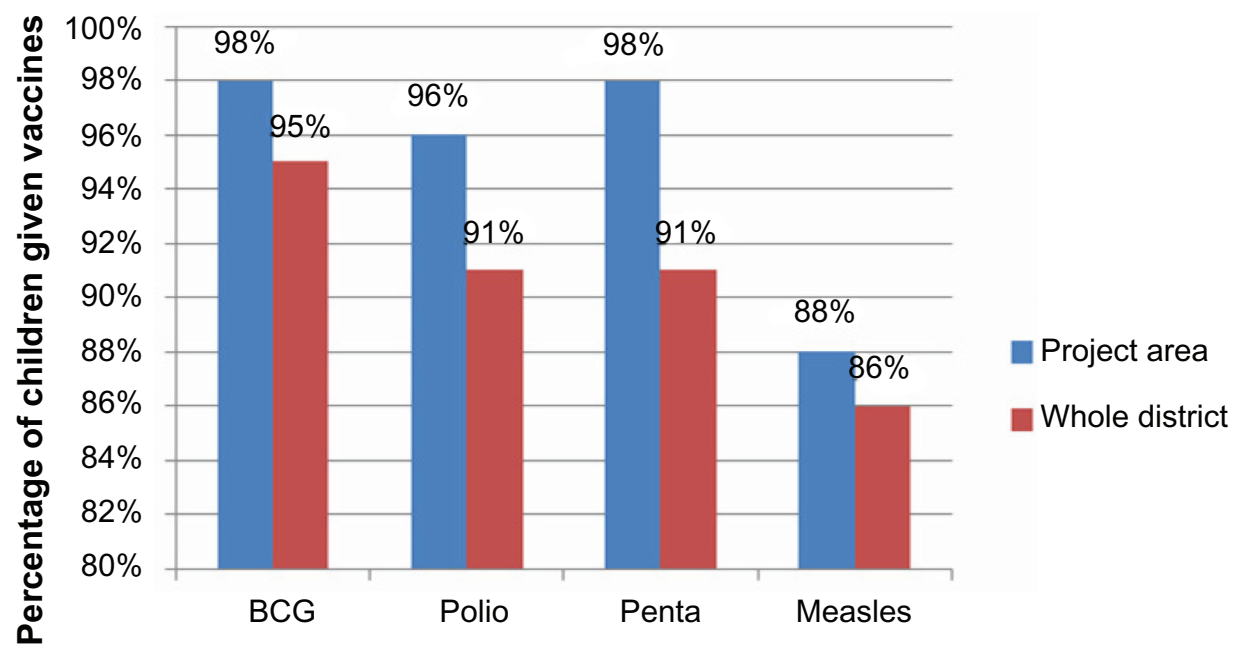

Figure 8 Vaccination coverage in the project area and the whole district.

Abbreviations: BCG, Bacillus Calmette-Guérin tuberculosis vaccine; Penta, pentavalent vaccine.

vaccines, and $82.3 \%(n=329)$ had received vitamin $A$. The district facility records, however, revealed that the project area had higher immunization coverage as compared to the whole district (Figure 8). Additionally, the study revealed a statistically significant relationship between the level of education of the mother and her ability to secure all needed vaccinations for her child $(P=<0.5)$.

\section{Malaria prevention}

The study established that $88.3 \%(n=353)$ of respondents did not consistently use insecticide treated nets (ITNs) to prevent malaria. It was revealed that some women did not use ITNs because of myths and beliefs that consistent use of bed nets caused difficulties in breathing, development of skin rashes, and issues in male sexual function.

\section{Men's participation in childcare}

Figure 9 shows the type of support that mothers had received from their male partners at different occasions in maternaland childcare.

\section{Discussion}

\section{Knowledge of women on antenatal care}

All the participants in this study, regardless of demographic characteristics, gained an understanding of the value of antenatal care during pregnancy. This is a positive outcome because knowledge could promote effective utilization of antenatal services which significantly contribute to reduction of maternal and neonatal mortality rates. ${ }^{13}$ Similar studies have found that knowledge of antenatal care promoted utilization of antenatal services. ${ }^{14}$ Our results, however, showed that women did not have comprehensive information on antenatal care. Very few women knew the recommended number of visits for women to make during the antenatal period, or when to begin attending antenatal care. Similar findings showed that the level of knowledge regarding the importance of early antenatal care was low. ${ }^{15}$ Maternal and child health is adversely affected when women know neither when to begin receiving timely antenatal care services, nor the number of visits to make to the antenatal clinic. Furthermore, fewer antenatal care visits could result in the lack of or delay in identification and management of perinatal complications, and lead to maternal deaths. The United Nations World Health Organization recommends that women start attending antenatal clinic immediately upon realizing they are pregnant (but no later than the sixth week of pregnancy) and that they make four focused antenatal visits. ${ }^{16}$ The pregnant women in a previous study in Malawi had limited health and nutrition knowledge, due either to the limited content of the information that the nurses provided, or their own limited health and nutrition literacy skills. ${ }^{17}$

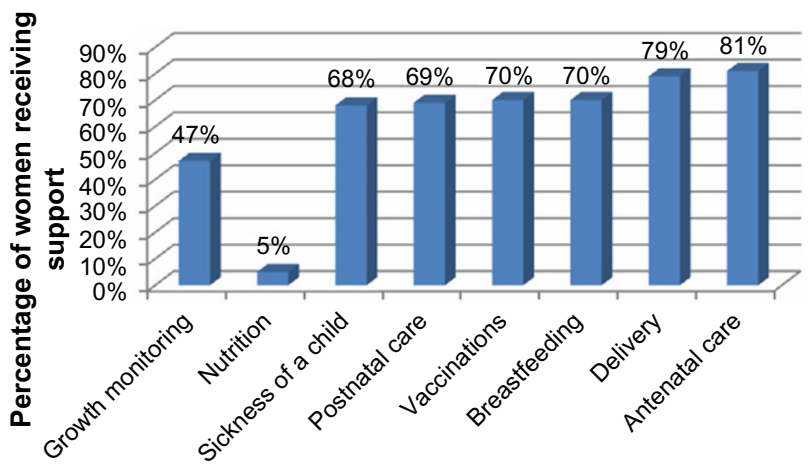

Figure 9 Type of support provided by males. 
Our study found that women's lack of comprehensive antenatal care information could be attributed to the fact that they did not receive adequate information when they met every month in their communities. This may reflect inadequate training in maternal and child health issues of the facilitators (HSAs). The HSAs do not seem adequately qualified to facilitate women's care groups because their training lasts only 6 weeks, while that of community midwives lasts 18 to 36 months. Content cannot be comprehensively covered in 6 weeks. For this reason, it is imperative that the project engages Community Nurse-Midwives or currently-trained community midwives to facilitate these women's group meetings.

Our study also revealed that many women do not have comprehensive information on the services provided at the antenatal clinic, as reflected in Table 2. If women lack comprehensive information on what is done at the clinic they cannot appreciate the importance of attendance. This may explain why less than half of the women made the recommended number of visits to the antenatal clinic. It further suggests the need to strengthen the information women get when groups meet, so that they may realize the importance of attending antenatal clinic.

\section{Place of delivery}

Although all respondents knew that the health facility was the ideal place for delivery, not all delivered there. The challenges faced were long walking distance, religious beliefs, lack of money for transportation, lack of permission from husband, and the perceived hostile attitudes of midwives. These findings corroborate previous research that women delivered at home because of lack of money, lack of transport, staff attitudes, tradition and cultures, and the pattern of decision-making power within the household, among others. ${ }^{18}$ The findings strongly justify and call for women's empowerment through education, as only $10 \%$ had attained lower high school. The model should also involve men, since Ntcheu is a patriarchal society in which the male is the primary authority and decision maker in the household. Clan and village chiefs should also be involved in the model because they are the custodians of Malawian culture. No meaningful development occurs in Malawi without the knowledge and influence of chiefs, who implement and monitor the development agenda of government.

The model should also encourage participation of Zionist church leaders, because in Malawi, this faith discourages its followers from accessing health care, including immunization of babies. There should be modification in the model to accommodate religion, since studies indicate that religion influences medical decisions. ${ }^{19}$ Antenatal care programs must be receptive to women of all faiths, so that they may learn and apply best antenatal health practices.

The fact that women delivered at a health facility did not mean they were automatically assisted by skilled health personnel. A lack of adequately skilled health personnel may have dissuaded some women from delivering at a health facility, and influenced them to deliver with the help ofTBAs. The use of TBAs contradicts policy advocated by the government of Malawi that every woman should be assisted by a skilled worker. ${ }^{20}$ It is important that the District Health Management Team (DHMT) ensures that all women be assisted by workers skilled in delivery, as this is one way of reducing maternal deaths. ${ }^{1}$ Women should be encouraged to go and await labor at the facility, to avoid home deliveries.

Under the initiative of the former president of Malawi, Her Excellency Dr Joyce Banda, maternity waiting homes will be built in all 26 districts of Malawi, resolving almost all the challenges faced by pregnant women.

Some women did not go to the health facility for fear of the perceived bad attitude of facility midwives. Similar findings revealed that women were compelled to deliver at home to avoid abusive language, lack of privacy, and degrading and unacceptable behavior of health care providers. ${ }^{18}$ The current study found a need for the Ntcheu DHMT to conduct ongoing supportive clinical supervision of midwives, to identify and correct the bad behaviors and attitudes of the midwives. Women should be empowered to report ill treatment encountered at the health facility so that authorities may develop specific strategies to eliminate it.

\section{Postnatal care}

That some women were lazy and ignorant about returning for postnatal checkup implies that they were not given adequate information during monthly meetings. In addition, some women failed to attend the health facility because of long geographic distance. This suggests a need for the government of Malawi to develop a health management system which brings maternal health services to communities. The initiative of training residential community midwives within their particular communities would solve this problem, provided the midwives were deployed in the rural areas where most needed. The goal of training community midwives is twofold: to give adequate and relevant information to women in remote areas, and to act as a bridge between the community and the health facility. Further, simple postnatal checkups could be performed by these midwives, thus solving most health problems associated with peuperium. Use of midwives in communities has been associated with positive outcome..$^{21,22}$ These studies revealed that postnatal women who were 
attended by community midwives showed that their mental health was significantly better than those who did not receive the care from community midwives. The current practice in Malawi is that newly-qualified community midwives are deployed in the health centers, contrary to the goal.

\section{Care of the newborn} Infant feeding

Although most respondents knew of exclusive breastfeeding, only half of them practiced it. This finding is not surprising, as the current exclusive breastfeeding rate for Malawi is only $57 \% .{ }^{23}$ Previous research findings are consistent with those of this study, that the number of women exclusively breastfeeding was low. ${ }^{24}$ This can be attributed to the culture in Malawi, where breast milk and supplements are given to babies simultaneously. Breast milk provides the nutrients a child needs during its first 6 months. Exclusive breastfeeding offers protection against diseases, thereby facilitating the survival, growth, and development of the child. ${ }^{25}$ The cultural context in Africa in general, and Malawi in particular, is that of collectivism as opposed to individualism. Children are regarded as a gift for the village or clan and not necessarily for the man and his wife only. This explains why more women, despite having knowledge on exclusive breastfeeding, are influenced by others in a collectivist culture on decisionmaking. ${ }^{25}$ There exists a need, therefore, to find concrete measures that reduce all barriers to exclusive breastfeeding by involving influential others or peer supporters.

It had been revealed ${ }^{26}$ that most women introduced light porridge to newly born babies just hours or a few weeks after birth. In most cases this was done with the influence of grandmothers, who, unfortunately, were excluded from the model. When children cried frequently, some mothers interpreted that as a sign of hunger and introduced weaning foods too early. These poor practices imply that women are not given adequate information. For instance, if women were informed that the more they breastfed, more milk would be produced, there would be no occasion to introduce supplements early, because babies would not be hungry and crying often. Best maternal health practice in Malawi would engage the grandmothers in monthly group discussions. They would then learn current effective practices of child rearing and, by virtue of their respected position in society, influence good practices in the care of neonates.

Other mothers delayed initiation of breastfeeding. This is contrary to government policy that every woman initiate breastfeeding within 30 minutes of delivery, and that every newborn baby be exclusively breastfed for 6 months. ${ }^{27}$ Failure to do this usually results in impaired bonding and malnutrition of the baby, because most new mothers cannot afford nutritious supplementary foods. This could be one of the factors contributing to cases of infant malnutrition.

\section{Malaria prevention}

The issue that ITNs were not used by most participants is not surprising, as the current rate of children under age five who sleep under ITNs is $25 \%{ }^{23}$ Discussions highlighted how beliefs in various villages discouraged consistent use of bed nets. These beliefs are that ITNs cause difficulties in breathing, the development of skin rashes, and cause males to avoid sex. This last belief is that men sleep so soundly under an ITN that sexual intimacy is reduced. Such beliefs contributed to more women not using ITNs consistently, thereby increasing susceptibility of themselves and their babies to malarial diseases. Non-use of ITNs thus supports the finding that myths and misconceptions hinder utilization of services. ${ }^{28}$ The tendency of families to receive mosquito nets free of charge, but not use them, raises the question of whether distribution of free ITNs is an effective way of preventing malaria. More emphasis and effort is needed in mitigating these myths and misconceptions, to help communities use ITNs properly.

The results of this study contradict previous research where use of bed nets was high because the culture valued them. ${ }^{29}$ This was despite the fact that the nets had to be purchased and not distributed free, as in Malawi. This aspect is in sharp contrast with how people use nets in rural areas of Malawi, especially along the shore of Lake Malawi. Citizens sometimes use ITNs as fishing nets or to fence vegetable gardens to prevent chickens from pecking at them. Male heads of households were responsible for purchasing the nets, because they were most directly involved in anti-malarial campaigns. ${ }^{29}$ In a similar manner, the model in the current study could be more effective if it more directly involved males.

\section{Vaccination}

More children were vaccinated in the project area than in non-project areas. This increase could be attributed to more preventable disease awareness campaigns conducted in project villages by the district health office, Safe Motherhood project, HSAs, and village volunteers. Despite this, the District Health Information System indicated that there were many cases of outbreak of vaccine-preventable diseases. This situation raises questions about the relationship between vaccination coverage and reduction of cases of vaccine-preventable diseases. There is speculation that in Ntcheu some cases come from Mozambique, which shares a border with Malawi. Another reason for vaccine-preventable diseases could be that some religious sects in Ntcheu prevent 
their followers from accessing medical services, including vaccines. A final consideration may be that the district health office did not manage the cold supply chain appropriately, rendering its vaccines less effective. It is imperative that Ntcheu DHMT do a tracer study to determine factors contributing to the outbreaks. At the same time, strict measures should be employed which ensure that all children under age 5 years receive required immunizations which protect them from vaccine-preventable diseases.

\section{Men's participation in childcare}

The participation of men in childcare helps to promote strong bonding, and the positive self-esteem and a sense of identity of children. Men as fathers and husbands make a positive difference when they actively take part in reproductive health issues. However, there are challenges which generally prevent men from actively participating in reproductive health issues. These challenges often prevent male community involvement in reproductive issues. Existing reproductive health services are not usually male-friendly, and most men are aware neither of good antenatal health practices nor of the danger signs in pregnancy. This model does not help matters because it deliberately excludes men from maternal and childcare practices. Some men actually prevented women from accessing antenatal services. It may be assumed that these males were unaware of the benefits of services. In addition, the support that husbands gave to their wives was mainly in the form of provision of transport money to health facilities, but not accompanying them. Lack of information on maternal and child health issues may have contributed to minimal support by men, and would concur with previous research findings that male involvement in the reproductive health of their wives is low in Malawi. ${ }^{30}$ This is ironic, because men exert a lot of influence on the reproductive health outcomes of women and children, ${ }^{31}$ but are not directly involved. It is encouraging that the government of Malawi is currently advocating for male involvement in maternal and child health issues. ${ }^{32} \mathrm{~A}$ deliberate effort is needed within the Safe Motherhood project model to complement government efforts by directly involving men. Project managers, and facilitators of women's groups within the model, should also devise mechanisms that motivate males to participate in antenatal groups.

\section{Limitations of the study}

This study involved only women who were enrolled in the Safe Motherhood project and were self-motivated to participate in the study. Consequently, the results may not reflect the knowledge and practices of individuals who had not been enrolled in the project.

\section{Conclusion}

There is a gap between women's awareness and knowledge of available maternal and child health care services, and utilization of these services. There is thus a need for comprehensive and sustainable information, education, and communication strategies, which also include men and elderly women, to ensure that maternal and child health knowledge is translated into effective practice.

While acknowledging that the project has helped improve women's ability to implement key maternal and childcare practices, better results would have been achieved with the active participation of other key players in maternal and child health, specifically men and elderly women. The effectiveness of maternal and child health practices is significantly diminished by the low level of support from husbands, and absence of the potential wisdom and experience of elderly women. The authors recommend maternal and child health interventions to actively involve men and elderly women since, in the Malawian context, a child is raised not just by the mother, but by all who live in the village. Additionally, elderly women are the guardians of those who are pregnant and in labor, and are traditionally a reservoir of experience into which young women can tap. We further recommend that this study be replicated at a larger scale to involve women outside the project, the elderly, and men.

\section{Acknowledgments}

The authors extend sincere gratitude to the following individuals for their encouragement: Dr David Pollard, Dr Rachael Chihana, Mr Elias Tembo, Ms Felistas Macheso, Ms Lucy Nyirenda, Mr Lazarus Maunda, Mr Tsilizani Mseu, and Mr Sipho Jale. We also thank Ms Barbara Hoyle for providing English language copy editing service. Our special appreciation goes to all enumerators and community women who participated in the study.

\section{Author contributions}

All authors contributed toward data analysis, drafting and revising the paper, and agree to be accountable for all aspects of the work.

\section{Disclosure}

The authors report no conflicts of interest in this work. 


\section{References}

1. National Statistical Office, Malawi and ICF Macro. Malawi Demographic and Health Survey, 2010. Zomba, Malawi: National Statistical Office and Calverton, MD, USA: ICF Macro; 2011. Available from: http://dhsprogram.com/publications/publication-FR247-DHSFinal-Reports.cfm\#sthash.FhByhPiA.dpuf. Accessed June 24, 2014.

2. Morrison J, Thapa R, Hartley S, et al. Understanding how women's groups improve maternal and newborn health in Makwanpur, Nepal: a qualitative study. Int Health. 2010;2(1):25-35.

3. Rath S, Nair N, Tripathy PK, et al. Explaining the impact of a women's group led community mobilisation intervention on maternal and newborn health outcomes: the Ekjut trial process evaluation. BMC Int Health Hum Rights. 2010;(10):25.

4. Nair N, Tripathy P, Costello A, Prost A. Mobilizing women's groups for improved maternal and newborn health: Evidence for impact, and challenges for sustainability and scale up. Int J Gynecol Obstet. 2012;119:S22-S25.

5. Manandhar DS, Osrin D, Shrestha BP, et al. Effect of a participatory intervention with women's groups on birth outcomes in Nepal: clusterrandomised controlled trial. The Lancet. 2004;364(9438):970-979.

6. Tripathy P, Nair N, Barnett S, et al. Effect of a participatory intervention with women's groups on birth outcomes and maternal depression in Jharkhand and Orissa, India: a cluster-randomised controlled trial. Lancet. 2010;375(9721):1182-1192.

7. Morrison J, Tamang S, Mesko N, et al. Women's health groups to improve perinatal care in rural Nepal. BMC Pregnancy Childbirth. 2005;5(1):6.

8. De Koning K, Martin M. Planning together: developing community plans to address priority maternal and neonatal health problems in rural Bolivia. Participatory Research in Health: Issues and Experiences. 1996:153-163.

9. Lemeshow S, Hosmer DW, Klar J, Lwanga SK. Adequacy of Sample Size in Health Studies. Chichester: Wiley; 1990.

10. Health Mo. Manual for Health Surveillance Assistants In: Health Mo, editor. Lilongwe Ministry of Health; 2008:1-20. Available from: http:// www.ccmcentral.com/documents/iccm-malawi-manual-for-healthsurveillance-assistants/. Accessed August 8, 2014.

11. Ministry of Education, Science and Technology. Malawi. National Education Sector Plan 2008-2017. A Statement. Available from: http:// www.scotland-malawipartnership.org/documents/37-NESPfullversion. pdf. Accessed August 8, 2014.

12. Braun V, Clarke V. Using thematic analysis in psychology. Qualitative Research in Psychology. 2006;3(2):77-101.

13. Health Mo. National Reproductive Health Strategy (2006-2010). In: Health Mo, editor. Lilongwe; 2010:19. Available from: https://www. k4health.org/toolkits/malawi-fp/national-reproductive-health-strategy2006-2010. Accessed August 8, 2014.

14. Alam YA, Qureshi AA, Adil MM, Ali H. Comparative study of knowledge, attitude and practices among antenatal care facilities utilizing and non-utilizing women. J Pak Med Assoc. 2005;55(2):53-56.

15. Rosliza AM, J MJ. Knowledge, attitude and practice on antenatal care among Orang Asli women in Jempol, Negeri Sembilan. Malaysian J Public Health Med. 2011;11(2):13-21.

16. WHO, UNICEF. Key Family and Community Childcare Practices; Participant's Training Manual. Lilongwe: Ministry of Health; 2005 $1-42$.

International Journal of Women's Health

\section{Publish your work in this journal}

The International Journal of Women's Health is an international, peerreviewed open-access journal publishing original research, reports, editorials, reviews and commentaries on all aspects of women's healthcare including gynecology, obstetrics, and breast cancer. The manuscript management system is completely online and includes
17. Kalimbira AA, Mvula N. Investigating Health and Nutrition Messages Given to Pregnant Women at Bwaila Hospital in Lilongwe [Master's Thesis]. Oslo and Akershus University College of Applied Sciences; 2011.

18. Mrisho M, Schellenberg JA, Mushi AK, et al. Factors affecting home delivery in rural Tanzania. Trop Med Int Health. 2007;12(7): 862-872.

19. Koenig HG. Religion, spirituality, and medicine: research findings and implications for clinical practice. South Med J. 2004;97(12): 1194-1200.

20. Health MMo. National Sexual and Reproductive Health and Rights (SRHR) Policy. In: Health Mo, editor. Lilongwe, Malawi: Malawi Government; 2009:1-42. Available from: www.who.int/ reproductivehealth/topics/linkages/RASmalawi.pdf. Accessed August 8, 2014.

21. MacArthur C, Winter HR, Bick DE, et al. Effects of redesigned community postnatal care on womens' health 4 months after birth: a cluster randomised controlled trial. Lancet. 2002;359(9304): 378-385.

22. Winter HR, Bick DE, Lilford RJ, et al. Redesigning postnatal care: a randomised controlled trial of protocol-based midwifery-led care focused on individual women's physical and psychological health needs. Health Technol Assess. 2003;7(37):1-98.

23. Office NS, UNICEF. Malawi Multiple Indicator Cluster Survey 2006. Lilongwe 2008. Available from: www.medcol.mw/commhealth/ publications/MICS Report.pdf. Accessed August 8, 2014.

24. Chatman LM, Salihu HM, Roofe ME, Wheatle P, Henry D, Jolly PE. Influence of knowledge and attitudes on exclusive breastfeeding practice among rural Jamaican mothers. Birth. 2004;31(4):265-271.

25. Sellers PM. Midwifery: A Textbook and Reference Book for Midwives in Southern Africa. Vol 1. Kenwyn, South Africa: Juta; 2011.

26. Bezner Kerr R, Dakishoni L, Shumba L, Msachi R, Chirwa M. "We grandmothers know plenty": breastfeeding, complementary feeding and the multifaceted role of grandmothers in Malawi. Soc Sci Med. 2008;66(5):1095-1105.

27. Health Mo. Infant and Young Child; Nutrition Policy. In: Health Mo, editor. Lilongwe: Ministry of Health; 1-7. Available from: https:/extranet.who.int/nutrition/gina/sites/default/files/MWI2013 Infant and Young Child Nutrition Policy and Guidelines.pdf. Accessed August 8, 2014.

28. Moore KM. Linking Women and Communities with Skilled Childbirth Care: Use of a Community-Designed Birth Preparedness Card in Western Kenya [draft]. Washington, DC: Manoff Group; 2003.

29. Panter-Brick C, Clarke SE, Lomas H, Pinder M, Lindsay SW. Culturally compelling strategies for behaviour change: a social ecology model and case study in malaria prevention. Soc Sci Med. 2006; 62(11):2810-2825.

30. Kululanga LI, Sundby J, Malata A, Chirwa E. Male involvement in maternity health care in Malawi. Afr J Reprod Health. 2012;16(1): 145-157.

31. Dudgeon MR, Inhorn MC. Men's influences on women's reproductive health: medical anthropological perspectives. Soc Sci Med. 2004;59(7):1379-1395.

32. Health Mo. National Sexual Reproductive Health and Rights Policy. In: booklet-Lilongwe MoHp, editor. Lilongwe: Ministry of Health 2009. Available from: www.who.int/reproductivehealth/topics/linkages/ RASmalawi.pdf. Accessed August 8, 2014.

a very quick and fair peer-review system, which is all easy to use. Visit http://www.dovepress.com/testimonials.php to read real quotes from published authors. 